\title{
HEMATOLOGICAL AND HISTOLOGICAL CHANGES INDUCED BY ADRENOCORTICOTROPIC HORMONE AND FORMALDEHYDE STRESSOR IN THE DOMESTIG FOWL
}

\author{
SHIGEHIRO MORITA AND SHIICHI NISHIDA
}

\author{
Department of Veterinary Anatomy, Faculty of Agriculture, \\ University of Tokyo, Tokyo
}

In mammals, the hematological changes of circulating blood and the histological changes of lymphoid tissues and adrenals induced by stressors, adrenocorticotropic hormone (ACTH) and cortical hormones have been much reported within recent years. Since the most of the previous works have been done on the mammals, it is of interest to study the hematological and the histological changes in birds. Very little works on these changes have been reported in birds.

It is known that adrenal cortical extract (ACE), ACTH and stressors, when injected into certain mammals, may cause a decrease in the number of lymphocytes and eosinophils in the circulating blood. In aves, even if these facts have not been proved enough, Shapiro and Schechtman (1949) reported that a single injection of ACE cause a transient lymphopenia and leucocytosis in the adult fowl. The increase was observed mainly in the heterophils. Weller and Schechtman (1949) also found that when ACE is injected into chick embryos on the 13th to 15th day of incubation, the number of lymphocytes is not changed significantly, but there is a marked increase in the number of polymorphonuclear cells. Stamler, Bolene, Katz, Harris, and Pick (1950) injected ACTH into chicks for a period of 5 days and reported that no effect was observed in the number of eosinophils.

The reinarkable differences are observed between mammals and birds on the structure of adrenal glands morphologically. In mammals, the adrenal glands differentiate into cortex and medulla. And their cortex consists of interrenal cells and medulla consists of chromaffin cells, three zones are present in the cortex. However, in birds, except in the brown pelican (Knouff and Hartman, 1951; Hartman, Knouff, and Howard, 1954), the zonation is not present in the interrenal tissue and appears in the form of irregular cords, among which the chromaffin tissues interdigitate intimately throughout the whole gland. This interrenal tissue contains either fuchsinophilic or pale cells (Uotila 1939).

In lymphoid tissues, there are remarkable differences between mammals and birds. No lymph nodes are observed in birds except in the natatores, and bursa Fabricii (cloacal thymus) is observed in all birds, but its functions are not well known. Recently Calhoun $(1935,1955)$ reported that the bursa Fabricii has a typical lymphoid structure (dense periphery with a lighter center). If the bursa

Received for publication March 15, 1956. 
Fabricii is a lymphoid organ, the same changes as found in the other lymphoid tissues should occure in the stress syndrome.

From these points of view, hematological changes and histological changes in thymus, spleen and adrenal, and also changes in bursa Fabricii of the domestic fowl during the stress, were studied.

\section{MATERIAL AND METHODS}

Hematological: In this experiment, male and female adult single comb white leghorn chickens were used. Body weight of the males and the females were about $2,000 \mathrm{gm}$ and $1,500 \mathrm{gm}$ respectively. Blood, obtained from vena profunda ulnaris or from comb after pricking by $1 / 1$ needle, were used. Each chicken was bled at the various intervals (3, 6, 9, 12 and 24 hours) after injection of ACTH. Blood smear preparations were fixed by methyl alcohol and stained with Giemsa solution. Two hundred leucocytes were counted under microscope with routine method. Ten mg of ACTH (Armour) diluted by $1 \mathrm{cc}$ of physiological saline was injected intravenously, intramuscularly, subcutaneously and intraperitoneally respectively. Control animals were injected with $1 \mathrm{cc}$ of physiological saline.

Histological: Single comb white leghorn cockerels were used in this experiment. The chicks $3 \sim 4$ weeks old were injected with $1 \mathrm{cc}$ of $4 \%$ formaldehyde intramuscularly, and two more injections were made with the same dose at intervals of 12 hours. In order to avoid shock, these injections were made slowly, filling about ten minutes. These animals were provided with food and water ad libitum, they were fed on crushed \#1 combined food (Nippon Haigo Shiryo Co.) supplemented with green vegetables. All animals were sacrificed at the end of the period of 12 hours after the last injection and weights of body, thymus, spleen, adrenal and bursa Fabricii were measured, then the tissues were fixed with Carnoy's and Helly's (Zenker-formol) fixertives, embedded with usual paraffin, cut at $4-6 \mu$, stained with hematoxylin eosin, toluidin blue (pH 7.0 buffered), Feulgen light green and Lillie's (1951) allochrome staining method (periodic-leucofuchsin, picro-methyl blue).

\section{OBSERVATIONS}

Hematological observations: Figure 1 shows percentage of heterophils and lymphocytes obtained from vein at the various intervals after physiological saline was injected intravenously. As seen in Figure 1, significant changes are not observed. Consequently, the intravenous injection and the bleeding from vein have no disturbal effect upon the percentage of heterophils and lymphocytes, Next four figures (Fig. 2, Fig. 3, Fig. 4, Fig. 5) show the changes of the leucocytes in the venous blood after $10 \mathrm{mg}$ of ACTH was injected intravenously, intraperitoneally, intramuscularly, and subcutaneously respectively. According to these figures, the intravenous or intraperitoneal injection of ACTH causes relative lymphopenia and heterophilia, while the intramuscular or subcutaneous injection of ACTH causes no changes in the venous blood. Figure 6 shows the changes of the leucocytes in percentage when the chicken was injected intramuscularly with $10 \mathrm{mg}$ of ACTH and was bled from comb by the pricking. Figure 7 shows the results when the chicken was injected intramuscularly with $1 \mathrm{cc}$ of physiological saline and was bled from comb by the pricking. According to the last two figures, the pricking of comb should have some disturbal effects upon percentages of heterophils and lymphocytes in the chicken. 


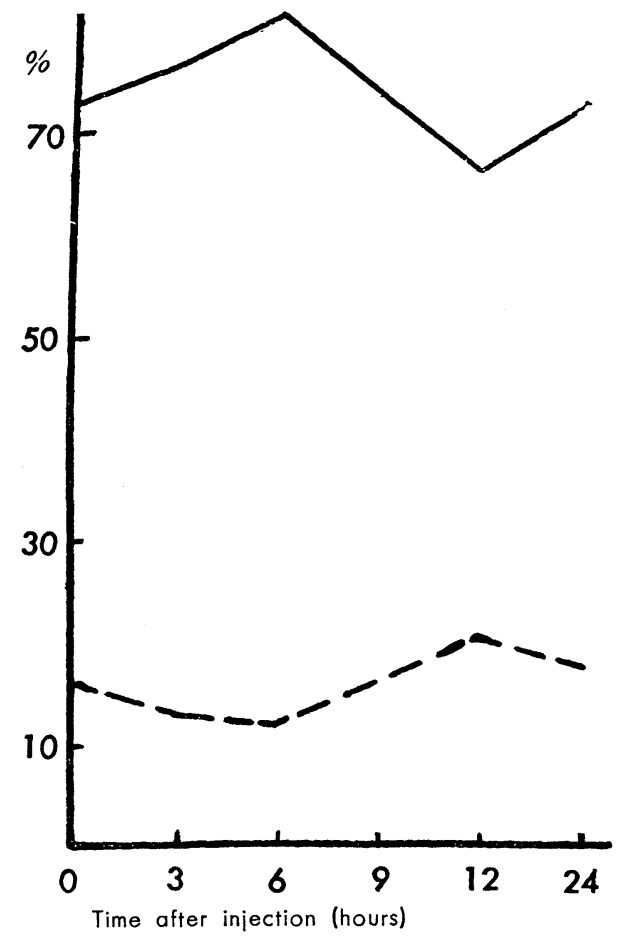

Fig. 1. Changes in percentage of heterophils and lymphocytes, when chicken was injected with physiological saline intravenously and was bled from vein at the various intervals.

- Lymphocytes. ---- Heterophils.

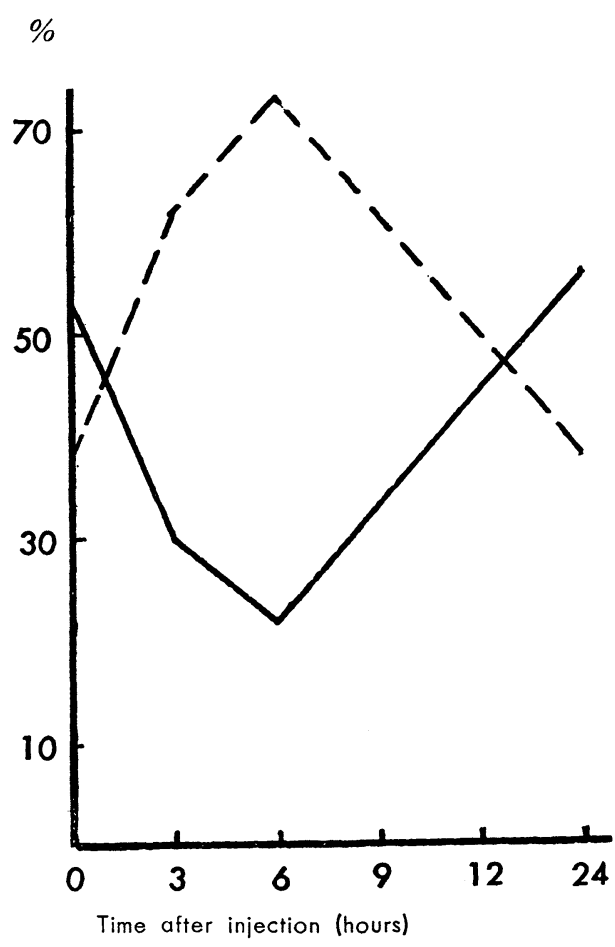

Fig. 2. Changes in percentage of heterophils and lymphocytes in the venous blood after $10 \mathrm{mg}$ of ACTH injected intravenously.

Histological observations: The visceral weights of the treated and the control animals are shown in Table 1. The weights of the thymus, spleen and the bursa Fabricii markedly decreased. In aves, this phenomenon has not been ascertained in the previous works. According to Bates, Riddle and Miller (1940), substances which usually cause alarm reaction, an outpouring of cortical hormones and hy-

Table 1. The weights of thymus, spleen, adrenal and bursa Fabricii of treated and control chicks (weight represented in $\%$ to body weight)

\begin{tabular}{ccccc}
\hline \hline No. & Thymus & Spleen & Adrenal & B. Fabricii \\
\hline 1 & 0.090 & 0.073 & 0.028 & 0.183 \\
2 & 0.066 & 0.073 & 0.020 & 0.202 \\
3 & 0.136 & 0.112 & 0.027 & 0.326 \\
Cont. 1 & 0.294 & 0.390 & 0.014 & 0.393 \\
Cont. 2 & 0.417 & 0.393 & 0.017 & 0.562 \\
\hline
\end{tabular}

cf. 0.012 (Breneman 1942) 


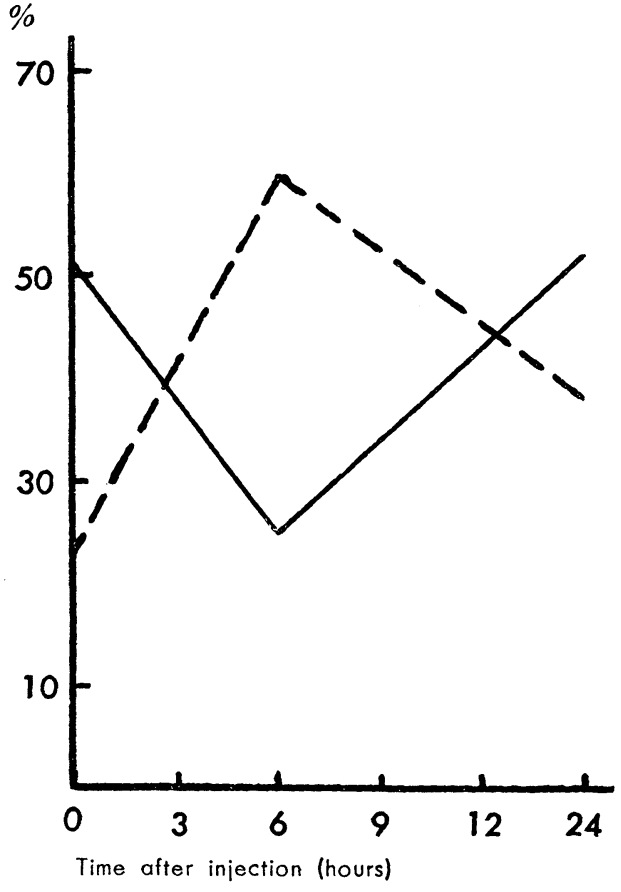

Fig. 3. Changes in percentage of heterophils and lymphocytes in the venous blood after $10 \mathrm{mg}$ of ACTH injected in$\%$ traperitoneally.

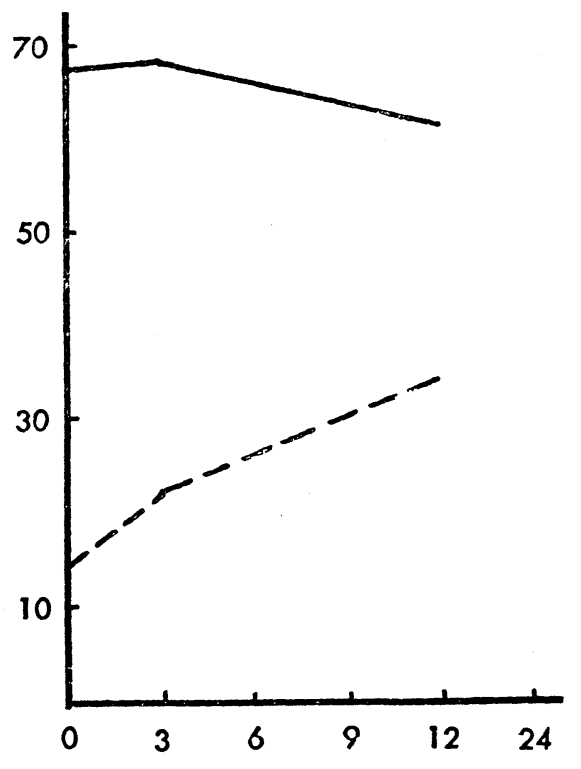

Time after injection (hours)

Fig. 5. Changes in percentage of heterophils and lymphocytes in the venous blood after $10 \mathrm{mg}$ of ACTH injected sub. cutaneously.

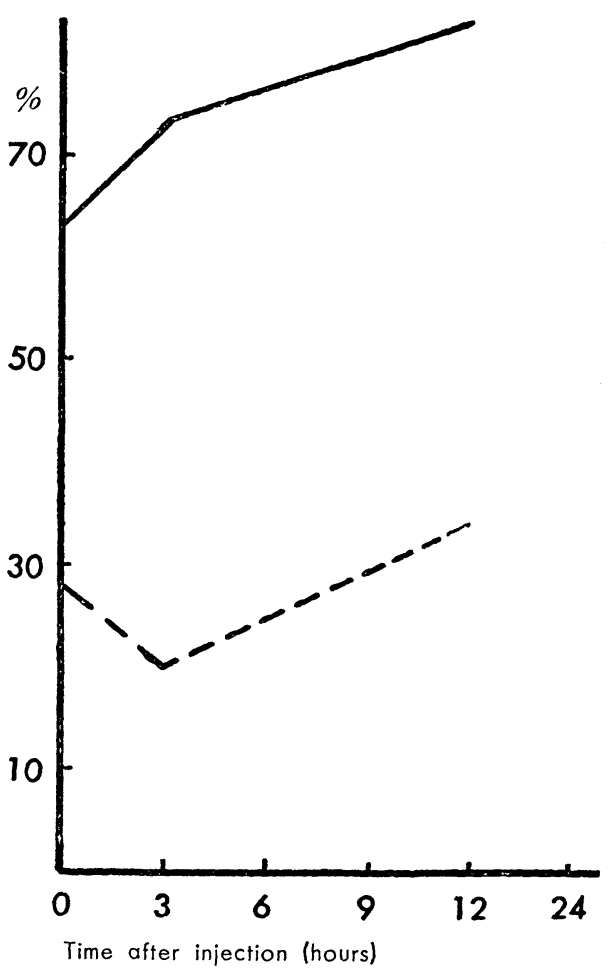

Fig. 4. Changes in percentage of heterophils and lymphocytes in the venous blood after $10 \mathrm{mg}$ of ACTH injected intramuscularly.

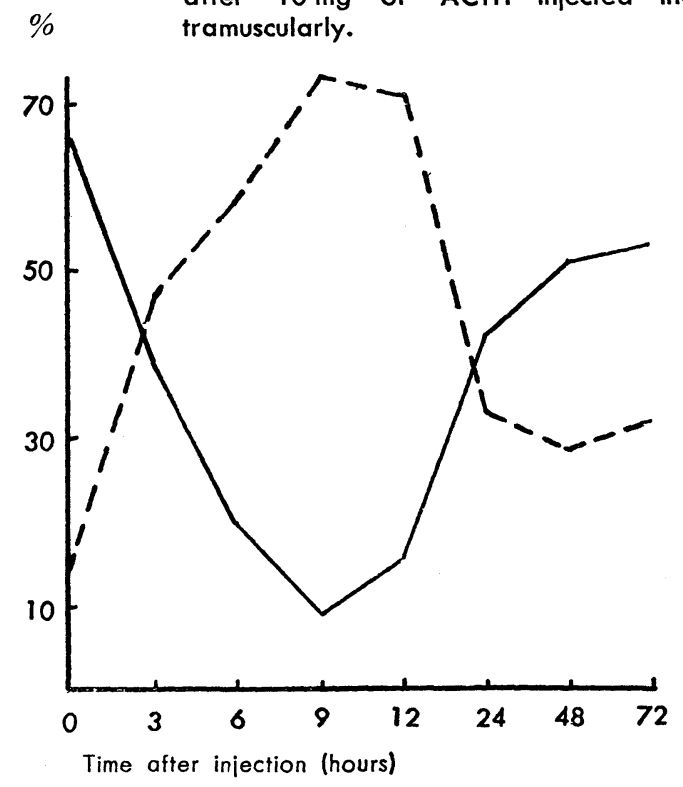

Fig. 6. Changes in percentage of heterophils and lymphocytes when chicken was injected with $10 \mathrm{mg}$. of ACTH intramuscularly and was bled at the various intervals from comb by priking. 


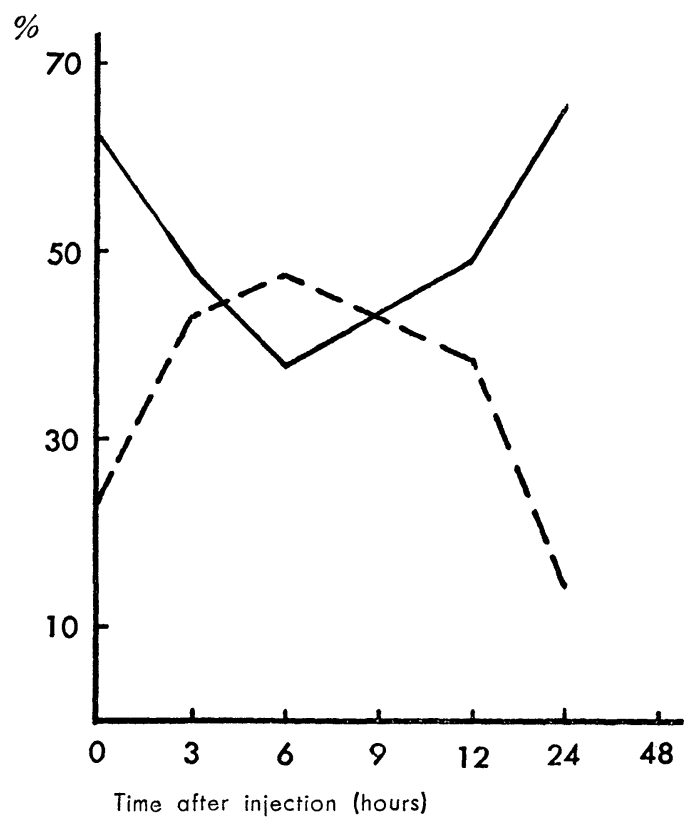

Fig. 7. Changes in percentage of heterophils and lymphocytes when chicken was injected with physiological saline intramuscularly and was bled at the various intervals from comb by priking.

pertrophy of adrenals in mammals, have littie or no effect on the young chick. Adrenal hypertrophy, however, can only be induced by ACTH in the pigeon (Miller and Riddle 1942) and in the young chick (Bates, Riddle and Miller, 1940).

Thymus: The weight of the thymus in the treated chicks markedly decreased. In mammals, this reaction is a typical and striking phenomenon which first appears in the stress syndrome. Many previous workers have confirmed this change (Selye 1937, 1950, 1951; Dougherty and White 1943, 1944, 1945; Baker, Ingle and Li 1951; Ehrlich and Seifter 1953).

The gland of chick is similar to that of mammals histologically. In the treated chicks, the thymocytes of thymus cortex drained into medulla, so that the demarcation between cortex and medulla became unclear, and naked reticular cells appeared in cortex. Marked karyorrhexis and pyknosis of the thymocytes and activation of the reticular cells-these changes were observed in the early stages of the stress syndrome in mammals (Selye, 1937, 1950; Dougherty and White 1945)-were not observed in the present study. These results agreed with the results of Baker, Ingle and $\mathrm{Li}$ (1951). In consequence of the decrease in the thymus weight, number of Hassal-body relatively increased, and PAS positive degenerating intercellular granules which differed distinctly from Hassal-body also seemed to increase in their number. Heterophilic infiltration was observed in the treated thymus. The shapes of nuclei of the heterophils were round or oval, not 
polymorphous, and their eosinophilic granules were oval and not rod, so that these heterophils appearing in this area should be young heterophils. These facts have not been reported in the previous papers. Eosinophilic infiltration which was observed by Spain and Thalheimer (1951), Tadokoro and Nomura (1954) and Kokoki (1954), was not observed in the present experiment.

Spleen: Though the spleen also decreased in its weight, its decrease was not so much as the thymus, but was obvious. Histologically, severe involution of the lymph follicle was observed in the white pulp, and the erythrocytes in the red pulp decreased in their number, consequently anemia was observed in the spleen. Activation of macrophages and degeneration of erythrocytes and lymphocytesthese facts were observed at the early stages (Dougherty and White, 1945) and not at the late stage of the stress syndrome in mammals (Baker, Ingle and $\mathrm{Li}$ 1951)-were not observed in the present experiment. Severe heterophilic infiltration was observed in the red pulp. The shapes of nuclei and eosinophilic granules of the heterophils were similar to those appeared in the thymus. It was suggested that heteropoiede appeared in the spleen and the thymus of the treated chicks. Though it was reported that polymorpholeucocytic infiltration appeared in spleen of mice and rabbits at the time of stress syndrome (Dougherty and White, 1945) and eosinophilic infiltration was observed by Spain and Thalheimer (1951) in mice and by Kokoki (1954) in rabbits, such infiltration was not observed in the present study. Baker, Ingle and $\mathrm{Li}$ (1951) observed erythropoiede in spleen of rat treated with ACTH. The heteropoiede in aves and the erythropoiede in mammals will be discussed later.

Adrenal: The weight of the adrenals in the treated chicks increased markedly, as shown in Table 1. This phenomenon has been confirmed fully in mammals. Hyperplasia and hypertrophy of the interrenal cells were observed. Consequently the area ratio of interrenal cell cords to chromaffin cell groups in the treated chicks was larger than that of the control chicks. The interrenal cell cords in the peripheral region of the gland were more hypertrophic than that in the central region of the gland. Many mitotic figures were observed in the interrenal cell groups. It seemed that these mitotic figures are observed more frequently in the peripheral region of the gland. Chromaffin substances in the chromaffin cells decreased very much as observed by Selye (1937) in mammals. In the control glands, staining differentiation between interrenal cells and chromaffin cells was observed when the section was stained by hematoxylin eosin or allochrome stain after fixed with Helly's fluid. This staining differentiation, however, was not found in the treated chicks as seen in Figure 13. These facts in the adrenals agreed generally with the results observed by Miller and Riddle (1942) in pigeons treated with ACTH.

Bursa Fabricii: The function of this organ is not known yet. Reticular structure of the bursa Fabricii rises from epithelial origin (Stieda, 1880; Osawa, 1911), and its follicle cells resemble to lymphocyte morphologically. The decrease in weight of the bursa Fabricii was observed as shown in Table 1. And involution of the follicle was found. However, other striking changes were observed neither histologically nor cytologically. 


\section{DISCUSSION}

Hematological changes of mammals treated with ACTH were fully discussed in recent years (Selye, 1950, 1951). The fact that ACTH produces the typical alarm reaction-neutrophilia, lymphopenia and eosinopenia-has been observed by many workers in mammals. However, in aves, the above mentioned fact is not confirmed nowadays as discribed in the introduction. In the present experiment, it was observed that ACTH causes relative heterophilia and lymphopenia. The fact that no hematological changes were observed as shown in the Figures $4 \& 5$, may be attributed to the results of insufficient dose of ACTH or species specificity. As shown in the Figures $6 \& 7$, pricking of comb should have some stressor agentical effects upon blood of the fowl. According to the present experiment and Shapiro and Schechtman's study (1949), the stress concept of Selye should be applicable in the chicken.

According to Bates, Riddle and Miller (1940), non-pituitary substances, which are either hormonal or other, although they were injected at nearly lethal levels, caused little or no enlargement of the adrenals of chicks. The substances tested were thyroxin, insulin, estrone, dihydroestrone, desoxycorticosterone, formaldehyde, ammonia, casein, zinc and copper sulfates, potassium chloride. According to Miller and Riddle (1942) adrenal hypertrophy and hyperplasia could be induced by ACTH injection or $4 \%$ formaldehyde, but cytological evidence of stimulation induced by $4 \%$ formaldehyde was doubtful in the pigeon. It has been generally said that the substances which usually cause the alarm reaction in mammals, have little or no effect in birds especially in histological aspects. However, in the present experiment, the histological changes similar to that of mammals were observed in the stress syndrome induced by $4 \%$ formaldehyde.

General histological changes of the thymus and the spleen of the treated chicks in the present experiment agreed with the results by Baker, Ingle and Li (1951) who injected adrenocorticotropin in rats during 21 days. Marked karyorrhexis and piknosis of the thymocytes and activation of the reticular cells were not observed. These facts are a striking character in two works; Baker, Ingle and $\mathrm{Li}$ (1951), and the present study. The PAS positive degenerating granules in the thymus of the treated chicks are probably identical with the substance which was found by Loenthal and Smith (1952) in the thymus of rats of the involutic stages as ages go, and was described as chromolipids.

The works did not agreed in respect of leucocytic infiltration. This fact may be attributed to the results of species specificity and time progress of the stress syndrome.

Heteropoiede of the spleen and the thymus in the present experiment and erythropoiede in the report of Baker, Ingle and $\mathrm{Li}$ (1951) in rats during the stress syndrome apparently seem to be contradictory. However, according to the fact that the second erythropoiede appears in the spleen of the rat embryo (Thiel and Downey, 1920, 1921), and that erythropoiede does not appear in the spleen of the chick embryo, and heteropoiede appears in the spleen of the chick embryo at the same embryonic stage (Sandreuter, 1951), it may be concluded that embryonic 
ability reappear in the stage of stress, either in the rat or the chick.

Histological changes of the adrenals in the treated chicks agreed with the results by Miller and Riddle (1942) generally. They injected corticotropin into pigeons during 4 16 days. It was observed in the present study that new interrenal cells were risen by mitosis in the peripheral masses of the whole adrenal gland, but any evidence of differentiation of interrenal cells from the capsule was not observed. It could not be confirmed that interrenal cells of the chick maintain some measure of activity apart from pituitary control as Miller and Riddle (1942) reported in their experiment on pigeons, because hypophysectomised chicks were not used in the present experiment.

The function of the bursa Fabricii is not well known. Jolly (1913b) stated that the beginning of involution coincided exactly with the appearance of sexual maturity, while Riddle (1928) found that involution was usually coincident with sexal maturity. Jolly (1911b) and Jolly and Levin (1911) found that fasting had a rapid degenerative effect upon the bursa Fabricii. According to the above mentioned facts, the bursa Fabricii should be thymus like organ. Calhoun (1933, 1954) said that the follicle of this organ was a dense lymphoid structure which was divided into a cortical and a medullary portion, the latter being less dense, as compared with the germ center of a lymph node. However, it is not fully proved that the bursa Fabricii is a lymphoid organ functionally. In this experiment, the decrease in the weight of the bursa Fabricii and the involutic change of its follicle were observed, while any other striking evidence, supporting the bursa Fabricii is a essential lymphoid organ, was not observed histologically or cytologically. So it can not be decided whether the bursa Fabricii is a essential lymphoid organ or not.

\section{SUMMARY}

In the present experiment, changes of percentage of leucocytes in the adult chicken blood induced by ACTH injection and histological changes of lymphoid tissues and adrenals in the young chick induced by formaldehyde stressor, were examined.

Hematological changes: Relative heterophilia and lymphopenia were observed in the treated chicks which were injected with $10 \mathrm{mg}$ of ACTH intravenously or intraperitoneally, and were not observed in the chickens injected with the same dose of ACTH intramuscularly or subcutaneously. It was found that pricking of comb has some stressor agentical effect upon blood in the fowl, and also it was suggested that Selye's stress concept should be applicable to the chicken.

Histological changes: Single comb white leghorn cockerels 3 4 weeks old were used. They were injected with $1 \mathrm{cc}$ of $4 \%$ formaldehyde intramuscularly 3 times during 36 hours. They were sacrificed at the end of the period of 12 hours after the last injection. The decrease in weights of thymus, spleen and bursa Fabricii and hypertrophy of adrenal gland were observed. Histologically, in the thymus of the treated chicks, the thymocytes of the thymus cortex drained into medulla, so that the demarcation between cortex and medulla became unvisible, and naked reticular cells appeared in the thymus cortex. The number of Hassal-body in- 
creased relatively, and the PAS positive degenerating intercellular granules also seemed to increase in their number. In the speen, severe involution of the lymph follicle in the white pulp, and heteropoiede in the red pulp were observed. Hyperplasia, hypertrophy, mitotic figures of the interrenal cells and loss of chromaffin substances in the chromaffiin cells were observed in the adrenal gland. In the bursa Fabricii, though involutic change of the follicles was observed, other striking changes could not be confirmed histologically or cytologically. From these facts, it could not be decided whether the bursa Fabricii is a true lymphoid organ or not.

These changes were comparable to those in mammals, and function of bursa Fabricii were discussed in the present parper.

\section{ACKNOWLEDGMENT}

The authors wish to express their hearty gratitude to Dr. K. Masui, Professor emeritus of University of Tokyo, for his suggestion and advice during the course of this work.

\section{REFERENCES}

Baker, B. L., D. J. Ingle and C. H. Li (1951). Am. J. Anat. 88, 313.

Bates, R. W., O. Riddle and R. A. Miller (1940). Endocrinol. 27, 781.

Breneman, W. R. (1942). Endocrinol. 31, 179.

Calhoun, W. L., Microscopic Anatomy of the Digestive Tract of Gallus domesticus, (1954). lowa. St. Coll. Press, Ames, Iowa.

Dougherty, T. F. and A. White (1943). Proc. Soc. Exp. Biol. and Med. 53, 132.

Dougherty, T. F. and A. White (1944). Endocrinol. 35, 1.

Dougherty, T. F. and A. White (1945). Am. J. Anat. 77, 81.

Ehrich, W. E. and J. Seifer. Schwartzman's the Effect of ACTH and Cortisone upon infection and Resistance. (1953). Columbia Univ. Press, New York. P 25.

Hartman, F. A., R. A. Knouff and G. A. Howard (1954). Anat. Rec. 120, 469.

Jolly, J. (1911b). C.R. Soc. Biol. 70, 498.

Jolly, J. (1913b). C. R. Soc. Biol. 75, 638.

Jolly, J. and S. Lewin (1911). C. R. Soc. Biol. 71, 320.

Knouff, R. A. and F. A. Hartman (1951). Anat. Rec. 109, 161.

Kokoki, K., T. Fukai, K. Yamaguchi and E. Chö (1954). Naibumpitsu 1, 388 (in Japanese).

Lillie, R. D. (1951). Am. J. Clin. Path. 21484.

Loenthal, L. A. and C. Smith (1952). Anat. Rec. 112, 1.

Miller, R. A. and O. Riddle (1939a). Anat. Rec. 75, (Suppl.), 103.

Miller, R. A. and O. Riddle (1939b). Proc. Soc. Exp. Biol. and Med. 41, 518.

Miller, R. A. and O. Riddle (1941). Proc. Soc. Exp. Biol. and Med. 47, 449.

Miller, R. A. and O. Riddle (1942). Am. J. Anat. 71, 331.

Osawa, G. (1911). Mitteil. med. Fak. Japan. Univ. Tokio 9.

Riddle, O. (1928) Am. J. Physiol. 86, 248.

Sandreuter, A. (1951). Acta Anat. Suppl. 14.

Selye, H.: (1937). Endocrinol. 21, 169.

Selye, H.: Stress. (1950). Acta Inc. Montreal, Canada.

Selye, H.: lst Anual Report on Stress, (1951). Acta Inc. Montreal, Canada.

Shapiro, A. B. and A. M. Schechtman (1949). Proc. Soc. Exp. Biol. and Med. 70, 440. 
Stamler, J., C. Bolene, L. N. Katz, R. Harris and R. Pick (1950). Fed. Proc. 9, 121. Stieda, L. (1880). Z. wiss. Zool. 34, 296.

Sturkie, P. D.: Avian Physiology (1954). Comstock Publ. Ithaca, New York

Tadokoro, S. and K. Nomura (1954). Kitakanto-Igaku 3, 111. (in Japanese).

Thiel, G. A. and H. Downey (1920-21) Am. J. Anat. 28, 279.

Uotila, U. U. (1939). Anat. Rec. 75, 439.

Weller, E. M. and A. M. Schechtman (1949). Proc. Soc. Exp. Biol. and Med. 72, 370.

\section{EXPLANATION OF PLATE I}

Fig. 8. Cross section of the thymus of the treated chick. the thymocytes of the thymus cortex drain into the medulla, so that the demarcation between cortex and medulla become unclear, and naked reticular cells appear in the cortex. Feulgen-light green stain, $\times 160$.

Fig. 9. PAS positive degenerating granules in the thymus of the treated chick are shown. Lillie's allochrome stain, $\times 600$.

Fig. 10. Cross section of the speen of the normal control chick. Lillie's alloshrome stain, $\times 160$.

Fig. 11. Cross section of the spleen of the treated chick, involution of the lymph follicies is shown. Lillie's allochrome stain, $\times 160$.

Fig. 12. Cross section of the adrenal of the normal control chick, the interrenal cells (light staining) and the chromaffin cells (darker staining) are shown. Hematoxylin eosin stain, $\times 160$.

Fig. 13. Cross section of the adrenal of the treated chick, hypertrophy and hyperplasia of the interrenal celis and disappearance of chromaffin substaces of the chromaffin cells are shown. Hematoxylin eosin stain, $\times 160$.

Fig. 14. Interrenal cell group of the adrenal of the treated chick, mitotic figures are scattered in the lower right of the figure. Hematoxylin eosin stain, $\times 600$.

Fig. 15. Hematopoietic figures of the heterophils in the spleen of the treated chick are shown. Hematoxylin eosin stain, $\times 1000$. 
PLATE 1
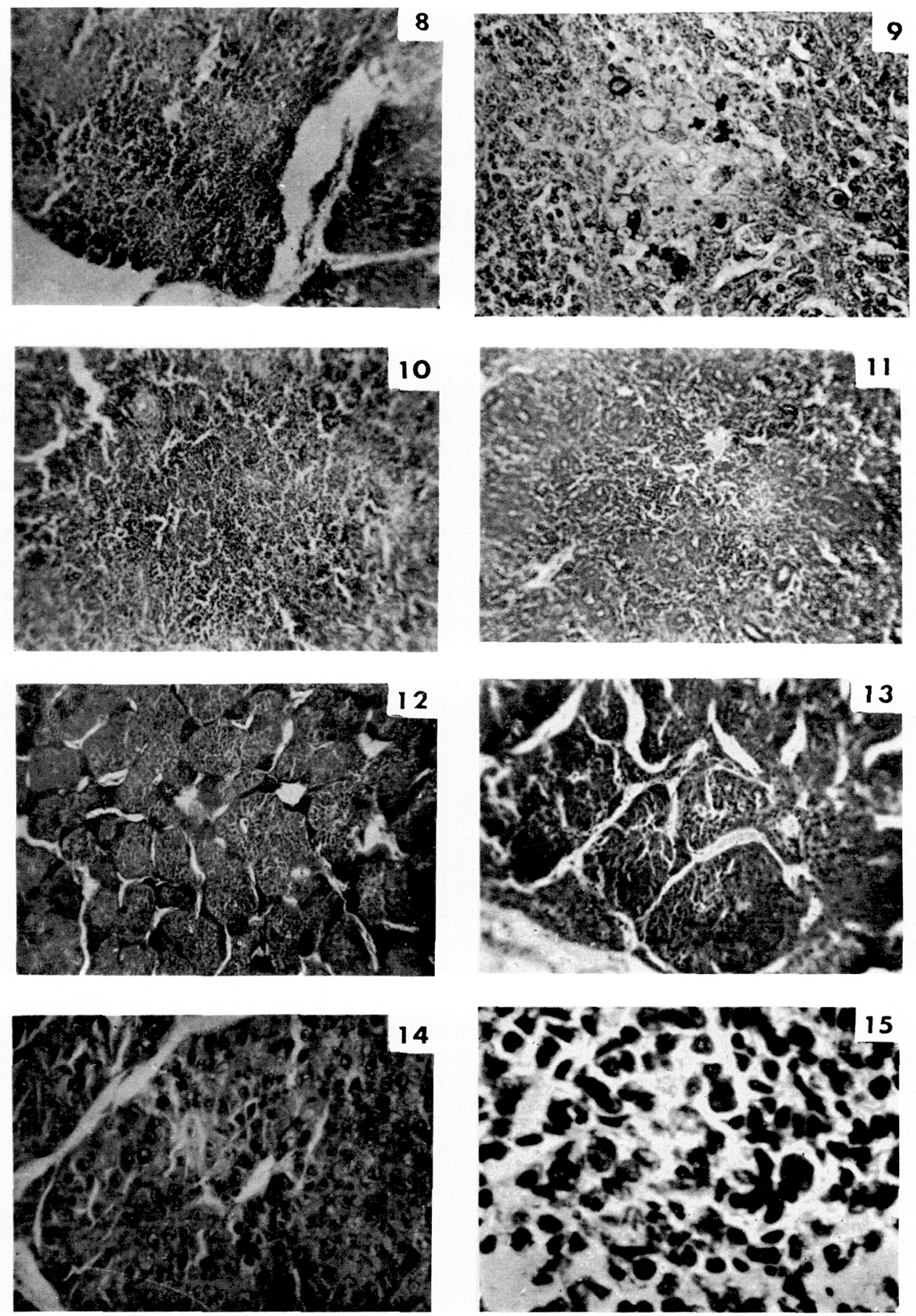